\title{
Retail Store Execution: An Empirical Study ${ }^{1}$
}

\author{
Marshall L. Fisher \\ Jayanth Krishnan \\ Serguei Netessine
Operations and Information Management Department
The Wharton School, University of Pennsylvania
[fisher, jayanth, netessine]@wharton.upenn.edu

December 2006

\begin{abstract}
We describe a methodology by which a retailer can identify action steps that are likely to increase sales and customer satisfaction and demonstrate the methodology using proprietary data from a large retailer with over 500 stores. We use monthly store-level data on a number of operational variables including in-stock rate, store staffing level as measured by payroll and store employee turnover, together with customer responses to satisfaction surveys. We develop a nested three-stage econometric model to analyze the marginal effects of various execution levers on sales, customer satisfaction and the percentage of customers who answer 'yes' to the question 'Did you find everything you were looking for?', which we term customer perceived in-stock. Our model explains approximately 75\%, 97\% and 71\%, respectively, of the residual variation in sales, customer satisfaction, and customer perceived in-stock. We find that customer perceived in-stock is primarily driven by actual in-stock and customer rating of employee knowledge; overall customer satisfaction is primarily driven by customer perceived in-stock, payroll level, customer rating of employee knowledge and check-out efficiency; and sales is primarily driven by actual in-stock, overall satisfaction and payroll level. Finally, we estimate relative magnitudes of these effects, propose specific actions to improve sales and estimate the likely sales increase from those actions. Our results suggest that a modest reallocation of the payroll budget among stores could be expected to yield a 2-3\% increase in sales with no increase in cost.
\end{abstract}

\footnotetext{
${ }^{1}$ We thank the Fishman-Davidson Research Center and P\&G-Gillette Corporation for their generous financial support for this project. We are also grateful to Andy Buteux, Daniel Corsten, Nicole DeHoratius, Vishal Gaur, Chris Ittner, Colin Peacock, the participants of the 2005 INFORMS conference in San Francisco, the 2006 COER conference in Philadelphia, the 2006 POMS conference in Boston, seminar participants at Duke University, Harvard University, MIT, Stanford University, University of Minnesota and numerous individuals interviewed for this project for their valuable insights and ideas.
} 


\section{Introduction}

It is sometimes said that success is the result of a good plan well executed. For a retailer, plans are mostly formulated at corporate headquarter and executed in their stores. Corporate planning functions include choosing the assortment of products to carry in each store at each point in time, setting store inventory levels and product prices, setting staffing levels, determining how many stores to have and where they are located and creating the physical design of stores and planograms that specify the location of all products within each store.

A retail store is an interesting amalgam of a factory and a sales office and store employees are responsible for a wide range of execution tasks that collectively determine the success of corporate plans. Factory related store execution tasks include receiving product, moving product from the back room to shelves as needed, putting items moved by a customer back to where they belong on the shelf and checking customers out. Fisher (2004) notes similarities between the execution tasks of a retail store and an automobile assembly plant, and suggests drawing on the Toyota Production System as a source of ideas for improving retail store execution. Sales office store execution tasks include all interactions with customers, such as greeting them, asking if they need help, and when requested, providing advice to enable them make a purchase decision and to find the products they have decided to buy.

Academic research to date has focused almost exclusively on planning functions. For example, the operations management literature includes numerous papers on inventory optimization that are applicable to setting planned inventory levels in a retail store. Recently, however, a few pioneering papers (Raman et al. 2001a, 2001b, DeHoratius and Raman 2003, Ton and Raman 2004, Corsten and Gruen 2003, Ton and Huckman 2005, Van Donselaar et al. 2006) have provided evidence of deficiencies in retail store execution, suggesting that optimized plans might be severely blunted by less than perfect execution. Although these papers have focused mostly on missing inventory, inventory record inaccuracy and inventory replenishment, it is reasonable to suspect that, given the high level of problems with inventories, other aspects of retail execution are imperfect also.

Interestingly, for many years, retailers have been administering surveys to their customers to measure both their overall level of satisfaction and their opinion of various details of their store experience. Many of the detailed questions relate to store execution. For example, 'Did you find what you were looking for?' is a commonly asked question directly related to the missing inventory issue noted above. It is thus natural to consider using this data to better understand issues related to store execution, including what factors influence the quality of execution and what is the impact of execution on output variables of interest to the retailer, such as sales and overall customer satisfaction. This paper reports an 
effort to do this using proprietary data obtained from a large retail chain with over 500 stores. The data is tracked monthly at the store level for a 17 month period and is comprised of 1) financial store performance data, including sales, number of transactions and number of units sold, 2) operational data, such as payroll, employee turnover, and in-stock levels, and 3) the results of ongoing customer satisfaction surveys that use a variety of questions to measure for a particular store visit a customer's overall satisfaction as well as their perception of various aspects of their experience that may have influenced their overall satisfaction.

We analyzed this data to discern correlates of 1) sales, 2) overall customer satisfaction and 3) the percentage of customers who answered 'yes' to the question 'Did you find everything you were looking for?', a metric we call customer perceived in-stock. Because we were interested in assessing the impact of the detailed variables on sales, satisfaction and customer perceived in-stock, we first transformed the data to attempt to remove spurious sources of correlation. For example, most variables were impacted by time, via trend and seasonality, and hence might be correlated with each other because of this common correlation with time, but this type of correlation was not of interest to us. We thus applied a data transformation procedure that (1) removes seasonality, (2) de-trends the data to control for store openings and economic trends, (3) removes forward-looking components from the data by accounting for managerial decisions that are based on the sales forecast, (4) controls for autoregressive properties and (5) standardizes the data to control for store heterogeneity. We then pooled this data panel and analyzed it using a nested three-stage model that explains the direct and indirect drivers of sales, overall customer satisfaction, and customer perceived product availability.

Our model explains approximately 75\%, 97\% and 71\% of transformed data's variations in, respectively, sales, overall customer satisfaction, and customer perceived product availability. We find that customer perceived in-stock is primarily driven by actual in-stock and customer rating of employee knowledge; overall customer satisfaction is primarily driven by customer perceived in-stock, payroll level, customer rating of employee knowledge and check-out efficiency; and sales is primarily driven by actual in-stock, overall satisfaction and payroll level.

We observe that stores within the chain vary greatly in their responsiveness to changes in controllable variables. For example, we find that increasing associate payroll by $\$ 1$ at a given store is associated with a sales lift of anywhere from $\$ 4$ to $\$ 28$, depending on the current level of payroll relative to store sales. The implication of this finding on retail performance is quite dramatic. We show that a modest reallocation of payroll from stores with low sales lift to stores with high sales lift could be expected to yield a $2.6 \%$ sales lift at no additional cost, a level of sales increase that is large relative to year to year changes in sales for mature stores.

The primary contribution of this paper is a methodology to help a retailer identify action steps 
that can increase sales, customer satisfaction and store execution. Although we designed this methodology to fit the specific data set that was available to us, we believe that it can be adapted to match the needs of other retailers. Our second contribution is to suggest, based on one retailer, findings about store execution that might apply to other retailers. While our findings are based on a data set whose extensiveness and richness are rarely, if ever, found in the literature, given that this data comes from a single retailer, we are uncertain of the extent to which our findings about drivers of sales and satisfaction would hold true for other retailers. We hope this study will stimulate additional research with other retailers, so as to identify common factors driving excellent execution.

The remainder of this paper is organized as follows. Section 2 surveys relevant literature, Section 3 describes our data set, Section 4 presents the transformation we performed on data prior to analysis and Section 5 describes our analysis and the resulting model. In section 6 we discuss our technical findings and in Section 7 we describe some managerial implications of our results.

\section{Literature Review}

Our research agenda on retail store execution straddles three existing areas of literature: 1) empirical studies of retail store execution, 2) literature on the relationship between customer satisfaction and financial performance in the retail industry and 3) empirical studies of execution in other industries such as retail banking and automotive manufacturing.

Retail store execution strategies have attracted the attention of researchers in operations management only recently, but this stream of work is most closely related to our paper. Perhaps the first reference on retail store execution is Salmon (1989) who argued that execution in retailing has become more important than other aspects of retail business (e.g., merchandising). DeHoratius and Raman (2006) analyze the relationship between incentives provided to store managers and monthly sales and shrinkage across a chain of stores. They control for store fixed effects, inventory, and advertising expenditures and, as in our work, find a positive and significant relationship between inventory and sales at the store level. The literature on missing inventory and inventory record inaccuracy in retailing (see Raman et al. 2001a, 2001b) found empirically that, because of execution failures, customers often do not find the products they seek, even if these products are within the store. Raman et al. (2001a, 2001b) report that over 65\% of the inventory records at retailer Gamma were inaccurate at the store-SKU level, and that over $16 \%$ of the inventory at retailer Beta was missing from the shelf. Their studies report that such issues arise mainly due to store and distribution center replenishment processes, merchandising, inventory management and employee turnover. DeHoratius and Raman (2003) outline three approaches to the inaccurate inventory problem: prevention and elimination of root causes (using methods similar to the 
Ishikawa process of JIT principles), correction and identification of errors through inspection policies, and lastly software solutions that integrate the source of errors into the inventory management system. In a follow-up study, Ton and Raman (2004) find that higher product variety and inventories lead to a higher incidence of phantom stockouts (such that inventory is in the back room but does not reach the shelf) and lost sales. Ton and Huckman (2005) study the impact of employee turnover on process conformance within retail stores and find that the negative effect of turnover is most pronounced in stores with low process conformance (lesser discipline in process execution and adherence to quality standards). Corsten and Gruen (2003) study the root causes of retail inventory stockouts and point to mechanisms that address the issue of stockouts and improve sales. Van Donselaar et al. (2006) find that store managers systematically made corrections on automated order advices either by shifting orders from peak days to non-peak days or by changing the order size. Fundamentally, this stream of literature has viewed retail operation from the factory lens while omitting the service delivery and customer-employee interaction aspects of retailing. For example, Fisher (2004) argues that both the auto plant and a retail store face a similar execution challenge of making sure what is needed arrives at the right time.

Literature on customer satisfaction is voluminous and spans several areas such as marketing, management and accounting. For example, numerous papers use the ACSI (American Customer Satisfaction Index) to study customer satisfaction at the company, industry and macroeconomic levels. For the purposes of our paper, we focus only on customer satisfaction studies that are immediately related to our work in retailing and do not survey the literature that studies the design of satisfaction survey instruments, because in this work we had no control over survey design. The basic tenet of this research stream is that higher service quality improves customer satisfaction, resulting in better financial performance, although the mechanisms by which this improvement happens vary. Iacobucci et al. (1994, 1995) provide precise definitions of service quality versus customer satisfaction. They contend that service quality should not be confused with customer satisfaction, but that satisfaction is a positive outcome of providing good service. Ittner and Larcker (1998) provide empirical evidence at the customer, business-unit and firm- level that various measures of financial performance (including revenue, revenue change, margins, return on sales, market value of equity and current earnings) are positively associated with customer satisfaction. However, in the retail industry they find a negative relationship between satisfaction and profitability which may be because benefits from increased satisfaction can be exceeded by the incremental cost in retail. Sulek et al. (1995) find that customer satisfaction positively affects sales per labor hour at a chain of 46 retail stores. Anderson et al. (2004) find a positive association between customer satisfaction at the company level and Tobin's q (a long-run measure of financial performance) for department stores and supermarkets. Babakus et al. (2004) link customer satisfaction to product and service quality within retail stores and find that product quality has a 
significant impact on store-level profits. To summarize, research on customer satisfaction views employees as facilitators of the sales process who are critical to improving the conversion ratio, by providing information to the customers on prices, brands, and product features and by helping customers to navigate store aisles, finding the product and even cross-selling other products. The unique feature of the retail store execution problem is that it combines the factory and the sales components, but this stream of literature focuses only on the latter.

Empirical studies of execution span other industries as well. For example, retail banking is dominated by the sales function; Frei and Harker (1999) quantify the inefficiencies in process execution due to process design using Data Envelopment Analysis. Frei et al. (1999) study the impact of the aggregate process performance and process variation on the financial outcome using a sample of 135 bank branches. They report that process variation negatively affects financial performance. Another prominent focus on execution which takes the factory viewpoint is found in the automotive industry. In this context the role of process design and conformance has long been debated, and the virtues of the Toyota Production System are well documented. Womack et al. (1991) show that Toyota's competitive advantage arises from a combination of employee motivation, training, process designs and JIT techniques. Fisher and Ittner (1999) study the impact of product variety on automotive assembly plant operations and find that increased option content variability in car assembly has an adverse effect on plants' operational performance, which is manifested in higher total labor hours, overhead hours, downtime hours, rework and inventory levels. MacDuffie et al. (1996) find that parts complexity persistently impairs productivity.

Perhaps the closest to retailing are the streams of literatures studying customer satisfaction, operational failures and performance in the airline and healthcare industry, because these industries too combine factory and sales components of execution. Studies of execution in the healthcare industry focused on operational failures in the execution process (Tucker 2004) as well as on learning through these failures (Tucker and Edmondson 2003). Ren and Wang (2006a) empirically link process consistency and service quality while Ren and Wang (2006b) further show how service quality affects volume at US hospitals. Using data on customer complaints caused by operational failures in the airline industry, Lapre and Tsikriktsis (2006) find that customer dissatisfaction follows a U-shaped function of operating experience: first dissatisfaction decreases with experience because airlines learn but then dissatisfaction increases because customers increase their expectations of service. Tsikriktsis (2006) shows that the relationship between operational performance and profitability depends upon a company's operating model; “focused” airlines show a link between late arrivals and profitability, whereas fullservice airlines do not. Moreover, capacity utilization is a stronger driver of profitability for full-service airlines than for focused airlines. Anderson et al. (2006) find that drivers of customer satisfaction are 
affected by customer attributions of blame for service failures: namely, customer-employee interactions are less important when the customer attributes blame to the service provider.

\section{Data Description}

Our study requires detailed store-level and customer survey data which is not publicly available. To obtain these data we worked closely with a large national retail chain under conditions of anonymity and nondisclosure. Therefore, we are unable to reveal either the name of the retailer, or provide details on its product lines and retail segment. The data comes from more than 500 stores over a period spanning 29 months. The retailer operated its stores centrally so that the headquarters planned the assortment, prices, payroll and employee training. The store manager had the authority to hire and terminate employees using a planned payroll budget for the month as a guideline. The store manager's compensation was not contingent on monthly sales at the store. The retailer did not tailor product assortments to customer demographics or store size.

We obtained two types of data: financial and operational data collected by the retailer and the results of a customer survey administered by an independent company on the retailer's behalf. Financial and operational data were available for the 29-month period and customer survey data were available for four years. Since we did not have financial and operational data for a significant part of this period, we eliminated surveys that did not have matching store-level data. Moreover, customer surveys changed significantly over time, with the number of questions in each month ranging from about 10 to about 70. Answer scales varied over the years as well. To overcome this problem, we decided to focus only on 13 key questions that remained unchanged over a 17-month period and that, we believe, are most closely related to store execution policies. Thus, we limit our study to 17 months starting from January 2004. We summarize corresponding variables in Table 1 where we calculate descriptive statistics for each variable across stores over the period of study.

\section{Financial and operational data}

We use subscript $i$ to denote stores which range from 1 to 437 and we use subscript $t$ to denote time periods from 1 to 17 . We note that new store openings were quite common over the study period and naturally these new stores have many missing observations.

SALES, TRANSACTIONS and UNITS.SOLD denote, respectively, monthly sales in \$, monthly number of instances in which customers bought something in the store and monthly unit sales. Stores averaged \$436,032 in monthly sales but varied significantly (from \$77,000 to \$1,400,000). On average, there were 10,019 transactions and 34,035 unit sales per month per store indicating an average basket size of \$44 (SALES/TRANSACTIONS), approximately 3.4 (UNITS.SOLD/TRANSACTIONS) products per 
basket and approximately $\$ 13$ (SALES/UNITS.SOLD) average sales per product.

CLEARANCE is the dollar value of all products that were marked down and sold on clearance in a given month (not including advertised promotions or markdowns planned by the central office across the entire chain). An average store sold only about $\$ 2,000$ worth of merchandise per month on clearance. Store managers had discretion over which items went on clearance. We note that the maximum value for CLEARANCE is 7 times higher than the average value, indicating wide dispersion in the enactment of this practice relative to SALES where the maximum is only about three times higher than the mean. Clearly, CLEARANCE is only a proxy for a store manager's action to put products on clearance sales because we only know the amount that was actually sold.

OVERRIDE is the dollar value for all sales that required a managerial override. A managerial override happens at the discretion of the store manager, when the customer reports a damaged product or a wrong price sticker, at which point the manager may decide to override the price recorded in the system. On average, only about $\$ 1,000$ worth of merchandise in a given month required managerial override. Similar to CLEARANCE, there is a wide dispersion in OVERRIDE across stores (in that the maximum value is 9 times higher than the average value).

RETURN is the dollar value of all products that were returned per month and for which money was refunded to the customer. Returns might be reflective of store execution policies, because they are often caused by the lack of communication between customers and employees regarding product features. On average, a store had $\$ 73,000$ dollars of merchandise returned, or about $17 \%$ of sales. Variation in this variable is similar to variation in SALES in that the maximum value is about three times the average.

MOS (marked out of stock) is the dollar value of all items that customers found in the store, but which the store's computer showed as out of stock. On average, only about $\$ 8,000$ worth of merchandise was marked out of stock in a given month, but this number varied somewhat from store to store (the maximum value of MOS is 4.5 times the average). Note that MOS can be viewed as a proxy for inventory record inaccuracy although it does not account for cases in which the item is in the computer system but is not in the store and it only accounts for situations in which customers "correct" the inaccuracy. Clearly, overall inventory record inaccuracy can be much higher.

ASSOCIATE.PLAN.DOLLARS and MANAGER.PLAN.DOLLARS are payroll budgets for each store for a given month. Payroll budgets are based on the expectation of sales in a given month. On average, a store planned to pay $\$ 23,657$ per month to associates and $\$ 20,047$ to managers per month which, in total, amounts to about $10 \%$ of sales.

ASSOCIATE.DOLLARS and MANAGER.DOLLARS are actual payrolls for store associates and managers in a given month. The store manager can deviate from the store payroll budget based on the number of new terminations, absenteeism and immediate needs. Thus, both random events and the 
store manager's decisions cause deviations. For example, if absenteeism is higher in a given month, the manager might end up spending less money on payroll than anticipated. On average, it appears that the actual payroll for associates is slightly higher than the planned payroll, but that the actual payroll for managers is somewhat lower than the planned payroll.

ASSOCIATE.TERMINATIONS and MANAGER.TERMINATIONS are the number of terminations at the associate and managerial levels, respectively. On average, 1.56 associates (which is equivalent to $6 \%$ ) and only 0.11 managers (which is equivalent to $1.9 \%$ ) were terminated (voluntarily or involuntarily) per month. These two variables are measures of turnover within the store, which may affect store execution processes and customer satisfaction due to a lack of experience and knowledge continuity among new employees (Ton and Huckman 2005).

ESTIMATED.INSTOCK is the percentage of SKUs in stock at the end of the month. Such measure of inventory availability is quite standard in retail practice and we use ESTIMATED.INSTOCK as a proxy for physical inventory availability. Average ESTIMATED.INSTOCK for all stores was 93\%.

\section{Customer survey data}

The retail chain administered automated customer surveys over the phone. When customers paid their bill at the checkout, they were randomly chosen to answer a satisfaction survey. The point-of-sales terminal then printed an invitation to call a toll-free number to answer a series of questions using the numeric pad on the telephone; customers were entered into a lottery with a cash prize as a reward for participating in this survey. We obtained customer surveys over a four-year period, with the number of responses varying from 10,000 to 30,000 per month for the entire chain and constituting approximately 0.5\% of all customer transactions. Among 13 questions we focus on, most had "yes-no" (with 1 for yes and 0 for no) answers, except for those questions whose answers are indicated by the variables KNOWPRODUCT, KNOWBRANDS, KNOWPRICES and OVERALLRATING, all of which were rated on a 10-point Likert scale. Since this data is at the customer level, we use the time of visit and the store number reflected on every response to associate each response with a store-month combination. For yes/no questions we calculate the fraction of “yes" answers for each store-month combinations. For all other questions we calculate the equally-weighted response value for each store-month.

AISLEDEBRIS indicates the percentage of customers who found debris in store aisles. On average, customers experienced obstruction in aisles $18 \%$ of the time, but there was significant variability (from 5\% to 55\%).

GREETING is percentage of customers who were greeted in the store. On average, customers were greeted $73 \%$ of the time.

ASSTNEEDED is the percentage of customers who needed assistance, but were unable to find it. 
Customers could not find assistance $14 \%$ of the time, on average.

CHECKOUT is the percentage of customers who found the checkout to be quick and efficient. On average, the checkout process was efficient $90 \%$ of the time, with some variability (78\% to 98\%).

BEYONDREACH is the percentage of customers who were interested in purchasing a product, but found the product too high or too deep on the shelves. Customers could not reach for the item in $19 \%$ of the cases, on average.

CUSTOMER.INSTOCK is the percentage of customers who found everything that they were looking for in the store. We use this variable to measure customers' perception of in-stock, which averaged $76 \%$ for the entire chain. Since the question asked customers about their entire shopping basket, finding that even one out of several products was out of stock would trigger a "No" response to this question. Since an average basket had about 3.4 items, the answer to this question is quite close to what we would expect, given 93\% average ESTIMATED.INSTOCK $\left(0.93^{3.4}=0.75\right)$. Thus, we do not have evidence of significant phantom stockouts (Raman et al. 2001). However, it is possible that some customers simply left the store without buying anything (and hence did not respond to the survey) because they were unable to find products.

FINDINGPRICE is the percentage of customers who had difficulty finding the price of a product. On average, $15 \%$ of customers experienced this difficulty.

KNOWPRODUCTS, KNOWBRANDS and KNOWPRICES are indicators of how knowledgeable employees were with respect to products, brands and prices, respectively. Summary statistics indicate that all three of these ratings were generally between 7 and 9, on average.

WILLRETURN is the percentage of customers who said they will return to the store. On average, $99 \%$ of customers were planning to return to the store. This number had little variability (95\% to $100 \%)$.

VALUE is the percentage of customers who thought that they got their value for the money. On average, 93\% of customers believed that their value for money was adequate. This number had little variability (89\% to $98 \%)$.

OVERALL.RATING is the average customer satisfaction rating for the store on a particular visit relative to expectations. Average chain-wide satisfaction was 8.4 on a 10-point scale and varied from 7.9 to 9.17, on average. For comparison, Morgan and Rego (2006) find that average customer satisfaction in the US economy is 7.8 on the same scale.

Our data comes with several limitations. Ideally, we would like to use profit at the store level as a measure of financial performance, but this particular retailer tracked profit only at the chain level. Moreover, this retailer believed that store employees primary impact was on sales. This is because most decisions that would impact cost, including the level of inventory, the price paid for products, store 
employee payroll and the quality of store fixtures, were made centrally at corporate headquarters. Furthermore, we do not have customer-level data on the number of purchases by each customer in a month. Thus, we acknowledge the possibility that customers who shop often at the store may skew the results of the satisfaction survey because they respond more often (although the survey does ask customers to evaluate their experience on a particular visit, not their average experience, and therefore this bias may not be significant). We also do not have data on the number of customers who did not visit the store because they were dissatisfied or the number of customers who did visit the store but left without buying. These customers do not respond to the satisfaction survey and hence their absence might introduce additional biases. Overall, it would be helpful to supplement customer questionnaires with the results of independent audits, but this particular chain did not conduct such audits. The retailer also did not track other variables that could potentially help us better understand in-store operating policies. For example, we were unable to obtain data on the exact extent of compliance with store policies (e.g., the store manager's adherence to the planogram), shrink, etc. However, we made every attempt to obtain as much data as the retailer collected. Likewise, our data from the customer satisfaction survey is driven by data availability, since we did not participate in the survey design. That said, our analysis relies on a data set whose extensiveness and richness are rarely, if ever, found in the literature. The final data set we analyzed contained 6310 store-month data points for 437 stores over 17 months for which we have matching operational/financial data as well as results of customer surveys.

\section{Data Transformation}

We conducted exploratory analyses and questioned company employees regarding exact data collection procedures and the nature of their business. Further, we conducted preliminary data analysis by calculating descriptive statistics and pair-wise correlations. Based on this exploratory analysis, we eliminated several variables from our analysis. First, we determined that TRANSACTIONS and UNITS.SOLD are highly correlated with SALES (with pair-wise correlations more than .99). Hence, for the remainder of the paper, we focus only on SALES as our measure of financial performance. We repeated our analysis using the two other variables as measures of financial performance, and results were qualitatively the same. Furthermore, we determined that product returns did not vary significantly by store: in fact, we found that the RETURN variable is highly correlated (correlation >.99) with SALES, indicating that this number might be reflective of the nature of the product line itself rather than processes within the store. We therefore omit this variable from the analysis.

Among customer survey variables, we found that KNOWPRODUCTS, KNOWBRANDS and KNOWPRICES were all highly correlated (pair-wise correlations >.95), so we combine them into a single TOTKNOWLEDGE variable using equal weights (Kennedy 2003). Finally, we established that 
OVERALL.RATING is highly correlated with the variables WILLRETURN and VALUE (pair-wise correlations $>$.9). Thus, in the remainder of our analysis, we use only OVERALL.RATING as an overall measure of customer satisfaction which is in line with Morgan and Rego (2006) who found that average satisfaction scores have the greatest value in predicting financial performance. Moreover, we did not use WILLRETURN, because customers who live in close proximity to the store might return to the store even if they are unsatisfied. We did not use VALUE because it relies, in large part, on how reasonably priced the products in the store are, something that is beyond the control of the store manager. As a robustness check, we also attempted to use an equally weighted combination of all three of these measures, and results were qualitatively the same.

Even after eliminating these variables, we discovered that the data possessed several features that complicated analysis: it was seasonal; stores exhibited sales trends; some variables were endogenously codetermined (e.g., payroll was based on expected sales but sales were also a function of payroll) and others possessed autoregressive properties (e.g., satisfaction in the current month affected sales both for current and future months); and stores exhibited significant cross-sectional heterogeneity (e.g., in sales levels). In this section we describe the data transformation procedure we have employed to convert the raw data so as to control for all of these effects. The ultimate goal is to obtain the data set that would allow us to analyze "within-month" changes in the dependent variable (sales) and all independent variables that are devoid of long-term effects (e.g., seasonality, trends) and do not incorporate expectations for the future. Without this data transformation, we might observe effects due to a different mechanism than we seek to understand which would not allow us to discern the true causal mechanisms (e.g., how operational policies drive sales and satisfaction).

\section{Seasonality}

It is well-documented that retailers experience significant seasonality in sales (see Fisher et al. 2000), and consequently their staffing and inventory management decisions are subject to seasonal effects as well. Hence, some variables may exhibit a spurious correlation over time due to seasonality, which would confound the true relationship between them. Using exploratory analysis, we noticed that even variables such as customer satisfaction exhibited strong seasonality. Therefore we de-seasonalize all variables in the data. We use a multiplicative model of seasonality and estimate seasonal coefficients endogenously using chain-wide data for all stores and all months. Thus, we ignore seasonal differences among stores (because the sale of this particular merchandise is not strongly affected by geographical location but is strongly affected by holiday sales patterns) and we use data for each variable separately (e.g., we de-seasonalize sales using sales data and customer satisfaction using customer satisfaction data). In our data seasonality alone explained $45 \%$ of chain-wide variations in sales. Since results of the 
customer satisfaction survey were confined to 17 months only, we used responses to the OVERALL.RATING question to de-seasonalize all customer satisfaction data, because responses to this question were available for a 29-month period coinciding with the availability of operational data. Moreover, from the limited data that we had it appeared that seasonal patterns are similar among all survey variables. The resulting formula is:

$$
\bar{y}_{i t}=\bar{y}_{i t}\left(\sum_{(j, \tau)} \bar{y}_{i \tau} / \sum_{(j, \tau)} \bar{y}_{i \tau}\right), \forall \tau=m(t),
$$

where $\bar{y}_{i t}$ is any variable in the data set (see Table 1 ) and $\bar{y}_{i t}$ is the de-seasonalized variable, the subscript $\tau$ ranges from 1 to 12 and denotes the month of the year in which $t$ occurs, and $m(t)$ denotes the month (1 to 12) corresponding to $t$. We note that sales experiences wide seasonal fluctuations with coefficients ranging from 0.6 in April to 1.8 in December while satisfaction and in-stock vary less (from 0.8 in AprilDecember to 1.3 in January-March).

One notable flaw in our approach is that some high-sales events fall on different months in different years (e.g., Easter falls on March or April). There are several alternative ways to de-seasonalize the data, although the approach we use is quite standard. We could have de-seasonalized each variable for each store using only this store's data but it is not clear how to treat new stores that do not have enough historical data. We could have used an additive model of seasonality, i.e., $\bar{y}_{i t}=\bar{y}_{i t}+\varepsilon_{\tau}$. This approach, however, is questionable since sales vary widely by store. We could also de-seasonalize all variables using sales rather than this variable’s time series. However, we observed in the data that customer satisfaction exhibits very different seasonality from sales and therefore we could not justify this approach.

\section{Trends}

Long-term trends in the economy (such as changes in incomes, inflation and consumer preferences) often affect customer purchasing decisions (see Ittner and Larcker 1998). Strategic decisions such as the entry of a competitor might lead to growth or decay in sales and satisfaction (see Mittal et al. 2005). Additionally, in our data we found that the strongest source of trends was a pattern of sales growth in the two to three years after a store opened. For example, new stores in our data exhibited dramatic growth in sales and a decline in customer satisfaction, resulting in a spurious negative correlation between sales and satisfaction over time. Over the study period, 97 stores were opened and no stores were closed. To control for these effects, we de-trend each variable separately for each store using the linear trend model. We then use the error from this de-trending procedure as the de-trended variable as follows: 
$\bar{y}_{i t}=\alpha_{0 i}+\alpha_{1 i} t+\tilde{y}_{i t}$ where $\tilde{y}_{i t}$ is the de-trended variable (e.g., sales or associate payroll). In our data trends alone explained approximately $2 \%$ of variations in chain-wide deseasonalized sales but for many individual stores this number was much higher.

An alternative to this model is to use chain-wide de-trending, but doing so would not allow us to control for store openings and entry of competitors. Furthermore, we could employ a nonlinear trend model with higher-order polynomial terms. We believe that our simpler approach is reasonable; given the relatively short panel (only 17 months), nonlinear terms did not appreciably increase goodness-of-fit (as measured by $\mathrm{R}^{2}$ ).

\section{Forward-looking behavior}

The retailer we worked with based its decisions regarding associate and managerial payroll on the expectation of future sales. Namely, the corporate office provided the store manager with planned payroll which was obtained by extrapolating future demand from past demand at the store and combining it with judgmental forecasts. Thus, for example, a positive correlation between sales and associate payroll can reflect a staffing policy that plans higher staffing levels for higher sales forecasts, or it can reveal that associate payroll drives sales. Since we are interested only in the latter effect, we use planned payroll to resolve this endogeneity leading to the following estimation procedure: $\tilde{y}_{i t}=\alpha_{i}$ Planned. $\tilde{y}_{i t}+\hat{y}_{i t}$, where $\tilde{y}_{i t}$ is either ASSOCIATE.DOLLARS or MANAGER.DOLLARS (recall that these are defined as actual values of these variables), Planned. $\tilde{y}_{i t}$ is the planned value for the same variable, and $\hat{y}_{i t}$ refers to the deviation from expected/forecasted/planned value. By conducting this estimation for ASSOCIATE.DOLLARS and MANAGERS.DOLLARS independently, we remove the forward-looking (expectation) components of these variables. In this estimation, we capture any systematic deviations from planned payroll that a particular store manager might be making by the coefficient $\alpha_{i}$. Literature on forward-looking behavior (e.g., Erdem and Keane 1996) proposes more sophisticated Bayesian learning models to accurately impute learning that the firm makes based on past sales. Such techniques might be necessary when a proxy like planned payroll is not available.

\section{Autoregressive behavior}

Actions and service encounters in the current period can affect future sales and satisfaction. For example, a satisfied customer may buy more during the current trip to the store, but he can also buy more in subsequent visits. Since in this study we focus on immediate consequences of store execution, we wish to separate short-term and long-term effects. We studied partial autocorrelations in our data and found that such lagged effects are significant, so we control for them using the an AR(k) (auto-regressive of 
order k) model. In particular, we find that first-order partial autocorrelation coefficients are sizable (>.5) for operational variables and up to third-order partial autocorrelation coefficients are sizable (>.25) for customer satisfaction survey variables (other coefficients are <.1 indicating negligible higher-order autocorrelation). This is consistent with our understanding that customer satisfaction can have lasting effects (see Ittner and Larcker 1998), but store execution policies in the current month are unlikely to directly affect sales in the distant future. Thus, we use the AR(1) model $\hat{y}_{i t}=\alpha_{2 i} \hat{y}_{i, t-1}+\mathbb{y}_{i t}$ for financial and operational variables and the AR(3) model $\hat{y}_{i t}=\alpha_{2 i} \hat{y}_{i, t-1}+\alpha_{3 i} \hat{y}_{i, t-2}+\alpha_{4 i} \hat{y}_{i, t-3}+\mathbb{y}_{i t}$ for survey variables, where $\mathbb{y}_{i t}$ denotes the residual value of each variable after accounting for the autoregressive behavior. In our data first-order autocorrelation alone explained $14 \%$ of the chain-wide deaseasonalized and detrended sales. We use errors from the autoregressive model for subsequent analysis.

Our assumption of distributed lags (the stochastic trend) could also manifest itself in the form of unit roots. We tested the sales and payroll data for unit roots using Dickey Fuller and Augmented Dickey Fuller Tests (see Kennedy 2003) and encountered no instances of unit roots in these variables in our data set. We also performed the Durbin-Watson test (Kennedy 2003) to verify the presence of autocorrelation, but it was inconclusive for most of the stores.

\section{Store heterogeneity}

Stores in our data set are highly heterogeneous. For example, average monthly store sales vary from $\$ 77,060$ to $\$ 1,409,365$, and the standard deviation of sales varies from $\$ 50,406$ to $\$ 460,515$. This variation is a combined result of differences in store sizes, customer demographics, location, the presence of competition, and possibly the characteristics of store personnel. In this paper we do not attempt to discover the drivers of these differences, since we do not possess much of the needed data. Instead, to be able to pool the data together into a single panel, for a given store we standardize all variables using their average and the standard deviation over the 17 months as follows (see Pindyck and Rubinfeld, 1997). We define $\mu_{i}=\sum_{t=1}^{17} \mathbb{y}_{i t} / 17$ and $\sigma_{i}=\sqrt{\sum_{t=1}^{17}\left(\mathbb{y}_{i t}-\mu_{i}\right)^{2}}$ as the mean and the standard deviations of the variable $\mathbb{y}_{i t}$ over the study period. Using these definitions, we obtain standardized values as: $y_{i t}=\left(\mathbb{y}_{i t}-\mu_{i}\right) / \sigma_{i}$. The added benefit of this standardization process is that it transforms all variables into dimensionless quantities which can be compared across variables (raw data is measured in different units for different variables, but standardized data is measured in standard deviations from the mean). Thus, standardization makes it easy to compare the relative impact of each variable.

There are other ways to account for store heterogeneity, but we selected the above approach 
because we believe that it fits our goals best. To check robustness, we also attempted to use sample mean and sample moving average (instead of both the mean and the standard deviation) to standardize the data, but the overall fit as measured by adjusted $\mathrm{R}^{2}$ was worse. Although one intuitively expects high sales to correlate with high sales volatility, we found that there were exceptions to that intuition. Thus standardization with the mean or the moving average of sales was a poor technique for these stores. Another alternative would be to capture store heterogeneity using additive fixed effects (dummy variables). However, this approach does not result in standardized coefficients. Yet another alternative is the random effects model, which is popular when the data is sampled from a population. Our panel consists of the entire population of stores, and the use of random effects offers very little advantage in identifying execution shortfalls at each store. Another popular method employed in panel data

econometrics is the use of elasticities, i.e., $y_{i t}=\left(\mathbb{y}_{i t}-\mathbb{y}_{i, t-1}\right) / \mathbb{y}_{i, t-1}$, but this approach renders the error structure of the model log-normal (see Wooldridge 2002). In our model the non-standardized errors have already been controlled for seasonality, deterministic trends, stochastic trends and forward-looking behavior, so the model with elasticities would render any interpretation of the errors cumbersome. A difference operator can be used to circumvent the log-normal error structure, but this approach does not allow us to compare regression coefficients in the model.

To summarize, we have controlled for seasonality, deterministic trends, and forward-looking and autoregressive behavior as well as store heterogeneity. We have also standardized all variables and made all coefficients comparable with each other. Although the variables have been transformed using the above process, we retain the same names for the sake of brevity and continuity. Note that, instead of following the above data transformation process, we could have simply included additional variables (seasonal dummies, the linear time trend, planned payroll, etc.) into the final regression model itself. This approach, however, would inflate the goodness of fit of our econometric tests, since these dummy variables would explain a significant portion of variability in sales, satisfaction and product availability. Specifically, seasonality, trends and autoregressive behavior together explain $61 \%$ of variance in sales. Instead, we follow a more conservative approach and run our econometric model using only residuals from the above transformation.

\section{Econometric Model of Store Execution}

We pool individual-store stationary time series to obtain a total of 6,310 store-month observations. Correlations among transformed variables of interest are presented in Table 2 (for operational and financial variables) and Table 3 (for customer satisfaction survey variables). We note that there are several strongly correlated variables in both tables indicating a potential for multicollinearity. 
Chapter 11 of Kennedy (2003) discusses the potential pitfalls of multicolinearity. Variance Inflation Factors (VIF) are one measure that can be used to detect multi-colinearity. VIFs are a scaled version of the multiple correlation coefficients between a variable and the rest of the independent variables. If there is no correlation between a particular variable and the remaining independent variables then VIF $=1$ which is the minimum value. A value greater than 10 is an indication of potential multicolinearity problems. We did not encounter any VIFs greater than 10 in our data and therefore Maddala (2001, chapter 7) suggests that multicolinearity is not harmful either to the coefficient estimates or to their variances. Kennedy (2003) also suggests that collinearity does not pose a problem if the absolute values of tstatistics in regression estimations are greater than 2 and, for statistically significant estimates, our results pass this test.

Next, we use a nested three-stage model with observed variables (see Wooldridge 2002, Maddala 2001) comprised of a sales equation, a satisfaction equation and a customers' perceived in-stock equation.

\section{Sales equation}

$$
\begin{aligned}
\text { SALES }_{\mathrm{it}}= & \beta_{1} \text { ESTIMATED.INSTOCK }_{\mathrm{it}}+\beta_{2} \text { OVERALL.RATING }_{\mathrm{it}}+\beta_{3} \text { CLEARANCE }_{\mathrm{it}} \\
& +\beta_{4} \text { OVERRIDE }_{\mathrm{it}}+\beta_{5} \text { MOS }_{\mathrm{it}}+\beta_{6} \text { ASSOCIATE.DOLLARS }_{\mathrm{it}} \\
& +\beta_{7} \text { MANAGER.DOLLARS }_{\mathrm{it}}+\beta_{8} \text { ASSOCIATE.TERMINATIONS }_{\mathrm{it}} \\
& +\beta_{9} \text { MANAGER.TERMS }_{\mathrm{it}}+\varepsilon_{i t} .
\end{aligned}
$$

On the right-hand side the sales equation includes overall customer satisfaction

(OVERALL.RATING) plus all operational variables available to us. However, this sales model is incomplete unless we control for possible endogeneity between sales and customer satisfaction. For example, when store sales increase (possibly due to higher traffic), it is plausible that customer satisfaction could decrease, because more customers are vying for the limited resources within the store. For this reason, we use a set of instruments to identify OVERALL.RATING in a separate equation.

\section{Satisfaction equation}

OVERALL.RATING $_{\mathrm{it}}=\gamma_{1}$ ASSOCIATE.DOLLARS $_{\mathrm{it}}+\gamma_{2}$ TOTKNOWLEDGE $_{\mathrm{it}}$ $+\gamma_{3}$ MANAGER.DOLLARS $_{\mathrm{it}}+\gamma_{4}$ ASSOCIATE.TERMINATIONS $_{\mathrm{it}}$ $+\gamma_{5}$ MANAGER.TERMINATIONS $_{\mathrm{it}}+\gamma_{6} \mathrm{MOS}_{\mathrm{it}}$ $+\gamma_{7}$ CUSTOMER.INSTOCK $_{\mathrm{it}}+\gamma_{8}$ AISLEDEBRIS $_{\mathrm{it}}+\gamma_{9}$ GREETING $_{\mathrm{it}}$ $+\gamma_{10}$ CHECKOUT $_{\mathrm{it}}+\gamma_{11}$ BEYONDREACH $_{\mathrm{it}}+\gamma_{12}$ FINDINGPRICE $_{\mathrm{it}}$ $+\gamma_{13}$ ASSTNEEDED $_{\text {it }}+\varepsilon_{i t}$.

In the second equation, we attempt to identify variables that explain customer satisfaction using factory (CUSTOMER.INSTOCK, AISLEDEBRIS, CHECKOUT, BEYONDREACH and FINDINGPRICE) and sales (TOTKNOWLEDGE, GREETING) aspects of retail store execution. In this 
equation the variables ASSOCIATE.DOLLARS and MANAGER.DOLLARS control for resource availability within the store to perform both factory and sales functions. All independent variables in this model act as instruments for OVERALL.RATING in the sales equation. However, just as SALES and OVERALL.RATING could be codetermined in the sales equation, OVERALL.RATING and CUSTOMER.INSTOCK can be codetermined in the satisfaction equation. For example, more satisfied customers would, on average, buy more thus depleting inventory and decreasing in-stock availability for other customers. This observation requires resolving possible endogeneity using a third equation.

\section{In-stock equation}

$$
\begin{aligned}
\text { CUSTOMER.INSTOCK }_{\mathrm{it}} & =\eta_{1} \text { ESTIMATED.INSTOCK }_{\mathrm{it}}+\eta_{2} \text { ASSOCIATE.DOLLARS }_{\mathrm{it}} \\
& +\eta_{3} \text { TOTKNOWLEDGE }_{\mathrm{it}}+\eta_{4} \text { MANAGER.DOLLARS }_{\mathrm{it}}+\eta_{5} \mathrm{MOS}_{\mathrm{it}} \\
& +\eta_{6} \text { AISLEDEBRIS }_{\mathrm{it}}+\eta_{7} \text { ASSTNEEDED }_{\mathrm{it}}+\eta_{8} \text { BEYONDREACH }_{\mathrm{it}} \\
& +\eta_{9} \text { FINDINGPRICE }_{\mathrm{it}} \\
& +\eta_{10} \text { ESTIMATED.INSTOCK }_{\mathrm{it}} \text { :ASSOCIATE.DOLLARS }_{\mathrm{it}} \\
& +\eta_{11} \text { ASSOCIATE.DOLLARS:TOTKNOWLEDGE }_{\mathrm{it}}+\varepsilon_{i t} \cdot
\end{aligned}
$$

This third equation aims to discern drivers of the customers' perception of in-stock. Among variables on the right-hand side we include the variable pertaining to the physical presence of inventory in the store (ESTIMATED.INSTOCK), variables related to store execution policies (ASSOCIATE.DOLLARS, MANAGER.DOLLARS, MOS, AISLEDEBRIS) and variables capturing sales functions of the retail store through the interaction between customers and employees (TOTKNOWLEDGE, ASSTNEEDED, BEYONDREACH and FINDINGPRICE). The estimate for ASSOCIATE.DOLLARS was not statistically significant in this equation so to better understand its impact we introduced two interaction effects. We included the interaction term between ESTIMATED.INSTOCK and ASSOCIATE.DOLLARS because the presence of inventory or store associates alone may not result in better product availability, but the combination might. Likewise, the availability of associates who are not knowledgeable about products may not improve product availability, so we interacted ASSOCIATE.DOLLARS with TOTKNOWLEDGE.

We use a two-stage least squares estimation (2SLS, IV estimator) method (Wooldridge 2002) that takes advantage of the instrumental variable specification to identify the regression coefficients and the goodness of fit. The 2SLS estimator is a limited information estimator (see Wooldridge 2002 for details on limited and full information estimation). To ensure robustness, we also use a pooled system OLS/equation-by-equation OLS (Seemingly Unrelated Regression model, POLS estimation). The choice of the estimator is primarily driven by the nature of the data and the model specification consisting of the cross-section $i$, the time period $t$ and the three equations (SALES, OVERALL.RATING and CUSTOMER.INSTOCK). We do not have a strong theory for latent unobserved variables, and we pool 
data across stores. The variance-covariance matrix of the residuals and regressors is assumed to be independent of the cross-section by virtue of the normalization process. In lieu of the standardization process, one would have to use a FGLS (Feasible Generalized Least Squares) estimator to account for cross-sectional heterogeneity. Furthermore, to manage the longitudinal component, we approximate short-run dynamic behavior using forward-looking and AR(k) transformations, thus eliminating the need to use a dynamic estimation mechanism. That leaves us with the choice of estimating SALES, OVERALL.RATING and CUSTOMER.INSTOCK either independently or jointly. We perform and compare both of these estimations. See Wooldridge (2002) for an extensive and detailed exposition of these estimation techniques.

\section{Results and Discussion}

The results of both 2SLS and POLS estimations are summarized in Tables 4a-4c. The change in results from a simple POLS estimation to the 2SLS estimation sheds light on the role of instrumental variables and is discussed below. The majority of this section discusses the results of the 2SLS estimator, since it incorporates more information on the simultaneous equations than the POLS estimator. In all three equations, the F-test and the p-value (<.001) support the null hypothesis of simultaneous and linear sales, satisfaction and product availability regression models.

\section{Sales equation}

The POLS estimator reports that $\mathrm{R}^{2}=74.6 \%$. ESTIMATED.INSTOCK, ASSOCIATE.DOLLARS, OVERALL.RATING, MANAGER.DOLLARS and CLEARANCE are statistically significant in the 2SLS regression $(\mathrm{p}<.01)$. Judging by the relative magnitude of coefficients, ESTIMATED.INSTOCK (.176), ASSOCIATE.DOLLARS (.483) and OVERALL.RATING (.202) have the strongest impact on sales. While other studies have also demonstrated that customer satisfaction (Sulek et al. 1995, Anderson et al. 2004) and inventory availability (DeHoratius and Raman 2005) positively affect sales, the presence of associate payroll among impactful variables is new. We argue that store associates are instrumental in fulfilling both factory and service functions within the store. The reason is that store associates perform a variety of factory tasks, which include moving inventory from the back room to the shelf, conducting inventory audits, guarding against theft, updating price stickers, checking adherence to the planogram, etc. Moreover, store associates perform sales office tasks which involve all facets of customer-employee contact, such as explaining the location of the products within the store, helping customers to make brand decisions and manage their shopping baskets, etc. It is also reassuring to see that satisfied customers do buy more. Interestingly, the amount of merchandise sold on clearance (CLEARANCE, $\beta=.043$ ) has a much smaller impact on sales. Managerial payroll (MANAGER.DOLLARS, $\beta=.04$ ) has a positive and statistically significant impact on sales, but it is rather limited compared to the top three variables. 


\section{Satisfaction equation}

TOTKNOWLEDGE, CUSTOMER.INSTOCK, ASSOCIATE.DOLLARS, GREETING, CHECKOUT, FINDINGPRICE and MOS are statistically significant in the 2SLS regression $(\mathrm{p}<.01)$. The POLS estimator reports that $\mathrm{R}^{2}=97.1 \%$, indicating excellent goodness of fit. Comparison of absolute values of the regression coefficients in the 2SLS regression indicates that employee knowledge (TOTKNOWLEDGE, $\gamma=.571$ ) and customer perception of product availability (CUSTOMER.INSTOCK, $\gamma=.399$ ) have by far the strongest impact on the OVERALL.RATING. Thus, customer satisfaction is strongly influenced by both sales (TOTKNOWLEDGE) and factory (CUSTOMER.INSTOCK) functions. The overwhelming importance of TOTKNOWLDGE suggests that customers greatly value the role of employees as experts helping them to make decisions on prices, brands and product features. Payroll (ASSOCIATE.DOLLARS, $\gamma=.018$ ) impacts customer satisfaction less, but its role should not be underestimated, because the role of employees in factory and sales functions has already been partially captured by the CUSTOMER.INSTOCK and TOTKNOWLEDGE variables, respectively. As we would expect, checkout efficiency (CHECKOUT, $\gamma=.064$ ) is positively associated with customer satisfaction, whereas an inability to find the price (FINDINGPRICE, $\gamma=-.018$ ) and inventory record inaccuracy (MOS, $\gamma=-.016$ ) are negatively associated with customer satisfaction, results that we intuitively expect. It also appears that an employee greeting (GREETING, $\gamma=.032$ ) helps to improve customer satisfaction.

\section{In-stock equation}

\section{ESTIMATED.INSTOCK, TOTKNOWLEDGE, MOS, MANAGER.DOLLARS,} FINDINGPRICE, ASSTNEEDED and two interaction terms are statistically significant in the 2SLS estimation $(\mathrm{p}<.01)$. The POLS estimator reports that $\mathrm{R}^{2}=71.34 \%$. The relative magnitude of regression coefficients indicates that physical inventory availability (ESTIMATED.INSTOCK, $\eta=.218$ ) and employee knowledge (TOTKNOWLEDGE, $\eta=.597$ ) are the most significant drivers of customers' perception of product availability. Once again, we see that a combination of the sales function and the factory function facilitates product availability. However, it is very surprising that the impact of employee knowledge is almost three times as high as the impact of in-stock. We should note that payroll (ASSOCIATE.DOLLARS) itself is not significant but two interaction terms involving payroll are significant (ESTIMATED.INSTOCK:ASSOCIATE.DOLLARS, $\eta=-.056$, ASSOCIATE.DOLLARS :TOTKNOWLEDGE, $\eta=.041)$. The negative coefficient on ESTIMATED.INSTOCK:ASSOCIATE. DOLLARS suggests that inventory and employees are substitutes rather than complements. However, the interaction of payroll and service components (ASSOCIATE. DOLLARS:TOTKNOWLEDGE) has a positive impact on CUSTOMER.INSTOCK. Thus, knowledgeable employees are instrumental in facilitating product availability. Additionally, MANAGER.DOLLARS $(\eta=.032)$ and FINDINGPRICE 
( $\eta=.031)$ have small but positive impact on customers' perception of product availability. The fact that the customer needed employee assistance and did not find it (ASSTNEEDED, $\eta=-.021$ ) negatively impacts the perception of product availability, thus again pointing toward the crucial role of employees. Surprisingly, the proxy for the misplaced inventory (MOS, $\eta=.044$ ) has a positive relationship with product availability. We propose that MOS captures only the "positive” side of misplaced inventory (i.e., customers do find the product even though it is misplaced) and hence translates into higher product availability.

We note that employee and management turnover is not significant in any of our estimates. We believe that the reason for this finding might be that our measure of turnover includes voluntary as well as involuntary terminations, making it hard to distinguish between the positive and negative impacts of turnover. Likewise, AISLEDEBRIS and BEYONDREACH were never statistically significant, suggesting that obstructions that prevent customers from reaching products do not seem to play a big role in either customer satisfaction or the perception of product availability for this particular retailer.

\section{Endogeneity and simultaneous estimation}

The POLS estimator conducts equation-by-equation estimation and ignores the simultaneity of the three equations, whereas the 2SLS estimator incorporates some information about the simultaneity in the estimation process (see Maddala 2001 for a detailed exposition of limited information estimators). In our two estimations, coefficients of the regressors differ in both the sales and satisfaction equations. Notably, in the satisfaction equation, the coefficient of CUSTOMER.INSTOCK is higher and the coefficient for TOTKNOWLEDGE is lower in the 2SLS estimator, because the 2SLS estimator incorporates information about the instruments for CUSTOMER.INSTOCK. Possible reason is that OVERALL.RATING has a negative impact on CUSTOMER.INSTOCK because satisfied customers deplete inventory faster. Moreover, TOTKNOWLEDGE has a very strong direct effect on CUSTOMER.INSTOCK (as is evident from the third equation) in addition to affecting OVERALL.RATING directly. MANAGER.DOLLARS becomes insignificant in the 2SLS estimation, because it is very significant in the CUSTOMER.INSTOCK equation.

In the sales equation, the coefficient of ESTIMATED.INSTOCK decreases and the coefficient of the OVERALL.RATING increases in the 2SLS estimation relative to POLS estimation. The 2SLS estimate of the OVERALL.RATING coefficient .202 (>.138) is the gross impact of OVERALL.RATING on SALES, and the POLS estimate (.138) is an approximation of the net impact of OVERALL.RATING on SALES after accounting for the negative feedback effect of SALES on OVERALL.RATING. Moreover, whereas the 2SLS estimator shows the direct impact of ESTIMATED.INSTOCK on SALES (.176), the POLS estimator overestimates this coefficient (.223) by including the indirect effect (ESTIMATED.INSTOCK $\rightarrow$ CUST.INSTOCK $\rightarrow$ OVERALL.RATING $\rightarrow$ SALES) in its estimation. 
We summarize the results of 2SLS estimates in Figure 1, where we show only the explanatory variables that exert the greatest impact while keeping the diagram as simple as possible.

\section{Managerial Implications}

The research effort reported here is part of a larger project that includes Nicole DeHoratius as a member of the research team and three retailers in addition to the one discussed here. The overall project seeks to understand broadly what store operating policies lead to effective execution. As part of this broader project, we interviewed several dozen individuals, including executives at the four participating retailers, together with executives at other retailers and consultants and academics with expertise in retailing. Figure 2 depicts a conceptual model of store operations that is consistent both with these interviews and with the results of our data analysis. Each day a given customer traffic arrives at a store representing potential demand. A fraction of this potential demand converts to actual sales depending on how well the store executes. Potential demand may fail to convert to actual sales if the store fails on any of four key execution elements: 1) the product the customer wants to buy isn't in the store because of a stock-out 2) the customer needs help and can't find a store associate 3) they find an associate but the associate is not helpful or 4) the checkout line is too long. We do not intend this as a universal model that captures everything important in all stores for all retailers, but rather a parsimonious model that, given what we saw in our data analysis, appears to fit store operations of the retailer we studied. As one example of a factor omitted from this model that might be important to other retailers, several experts told us managing adjacencies of products to drive add-on purchases is important in some contexts.

If customers find what they came for and make purchase successfully, they leave the store satisfied, and are likely to return. Otherwise, they will abandon this retailer for a competitor with some probability. Thus, in this model, sales during the current visit increases satisfaction, which in turn leads to future visits and sales. This model is also consistent with many findings in the literature. Much of classical inventory management literature (see, e.g., Cachon and Terwiesch 2005) is predicated on the assumption that in-stock is a driver of sales. The role of the store associate in guiding customer purchase decisions is documented in the marketing literature (see Sulek et al. 1995, Iacobucci et al. 1994, 1995) as well as in studies of retail banking (Frei and Harker 1999). Iacobucci et al. (1994, 1995) document that satisfaction is an outcome of good service. Furthermore, DeHoratius and Raman (2003) document the role of store associates in getting products on the shelves and aiding customers in their search for the product

Our analysis provides sufficient data to assess the impact on sales of changes in store associate staffing. Note that given the data transformation to control for store heterogeneity, the coefficient of .483 on store associate payroll in the sales equation implies that increasing associate payroll at store $i$ by 
$\sigma_{\text {ASSOCIATE.DOLLARS } i}$ increases sales by $\sigma_{\text {SALES } i}$. We can thus calculate the increase in monthly store sales

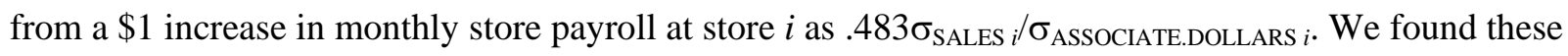
lift factors varied considerably across stores, ranging from a low of \$3.94 to a high of \$28.01.

One obvious question is what causes the variation in payroll elasticity across stores. To understand this, first note that intuitively one would expect a diminishing return on each additional store associate added (with an arbitrarily large increase in staffing, associates would eventually outnumber customers and additional staff would be expected to have little impact) and hence sales as a function of payroll should be a concave, non-decreasing function. Figure 3 shows sales vs. payroll for a representative store over time and we do indeed see this concave shape exhibited. The sales lifts we have computed for payroll increases are essentially the derivative of this curve at the current staffing level for each store. Hence, we hypothesize that those stores with high (low) lifts are currently staffed at a low (high) level relative to sale and hence are on the steep (flat) part of this curve. We examined the data and found that those stores with high lift values also had a high ratio of sales to associate payroll relative to stores with low lift values.

This retailer earns gross margins of about $40 \%$, so even for the lowest sales lift of 3.94 , incremental profit of $.4 * 3.94=\$ 1.58$ exceeds the additional $\$ 1$ expense. It thus appeared that this retailer would benefit from an increased staffing level at all stores. However, a significant increase in a major expense such as payroll is controversial and may have other ramifications. On the other hand, the allocation of staffing across stores via the planned payroll budget is something that is evaluated every month. Hence, we explored the use of our analysis to guide a better allocation of associate payroll across stores. We sorted the sales lift of stores open for at least one year in our data and found that the 236 stores with the lowest lifts had total monthly payroll of $\$ 5,375,052$ vs. a nearly equal value of $\$ 5,384,640$ for the remaining 201 stores with highest lift. Increasing monthly payroll by 25\% (an amount we judged to be within the range of linearity on the concave sales vs payroll curve) for the 201 stores with highest lift and lowering payroll by $25.05 \%$ for remaining stores would leave total chain payroll unchanged and increase sales by $2.6 \%$. Public retailers routinely report sales increases in stores open at least one year, called comp sales. Generally comp sales range from negative to the low single digits, so a $2.6 \%$ sales increase is significant. Retailers also use a large number of part time employees and by varying the hours of these employees it's possible to vary payroll nearly continuously.

We also computed the increase in sales at each store from a $1 \%$ increase in in-stock. These factors had a 92\% correlation with store sales and varied nearly linearly with store sales, consistent with a model that stock-outs simply reduce store sales in proportion to the level of stock-outs. Lift factors average 20\% of sales, suggesting that when a customer encounters a stock-out, they substitute with another product $80 \%$ of the time. This is the only study we are aware of to present evidence of customer stock-out rates in 
a large scale situation. Note that the 'factor of production' analogous to store payroll is not in-stock, but the inventory which drives in-stock. While we found that sales varies linearly with in-stock, in-stock as a function of inventory is a concave non-increasing function, and hence sales vs. inventory has the same form as sales vs. associate payroll.

Clearly, with both inventory and payroll, there is an optimal level at which marginal return equals marginal cost. It is difficult to find this optimal level directly for payroll because our analysis provides only the derivative of a non linear curve. However, we were able to suggest an improving adjustment to payroll, and this process repeated over time would tend to an optimal point. If one assumes the $80 \%$ substitution rate inferred by our analysis applies across all products, it would be possible to conduct SKU level analysis using known theory to find inventory levels that minimize the cost of lost margin due to stockouts and carrying costs.

Clearly, results of our analysis should be used with caution because they are limited to the particular retailer that we studied. For example, the impact that employee knowledge has on customers' perception of product availability will probably differ between grocery and electronics retailers. By extension, the relative importance of the sales and the factory functions will differ from retailer to retailer as well. However, we do believe that the methodology we propose is quite general and can be applied by other retailers that conduct surveys of customer satisfaction and track operational metrics within the store.

Although we focused on explaining month-to-month variations in sales, satisfaction and product availability, we might pose a different question: What explains the average and standard deviation of sales at different stores (the cross-sectional study)? We suspect that the main factors in such a study will be customer demographics, the presence of competition, physical store characteristics, advertising, and the characteristics of store employees and managers, among others. The only previous study that focuses on explaining cross-sectional variations in retail store performance, at least that we are aware of, is Hise et al. (1983), who find that the number of employees, inventory, store size, fixed assets and employee tenure with the company are associated with sales, to a statistically significant degree.

\section{References}

Anderson, S. W., L. S. Baggett and S. K. Widener. 2006. The impact of service operations failures on customer satisfaction: the role of attributions of blame. Working paper, Rice University.

Anderson, E.W., C. Fornell and S. K. Mazvancheryl. 2004. Customer satisfaction and shareholder value. Journal of Marketing, 68(4), 172-185.

Babakus, E., C. C. Bienstock, and J. R. Van Scotter. 2004. Linking perceived quality and customer 
satisfaction to store traffic and revenue growth. Decision Sciences, 35(4), 713-737.

Cachon, G. and C. Terwiesch. 2005. Matching Supply with Demand: An Introduction to Operations Management. $1^{\text {st }}$ ed., McGraw-Hill.

Corsten, D. and T. Gruen. 2003. Seeking on-shelf availability—an examination of the extent, the causes and the efforts to address retail out-of-stocks. International Journal of Retail and Distribution Management, 31(12), 605-716.

DeHoratius, N. and A. Raman. 2003. Building on foundations of sand? ECR Journal, 3(1), 62-63.

DeHoratius, N. and A. Raman. 2006. Store management incentive design and retail performance: an exploratory investigation. Forthcoming in Manufacturing \& Services Operations Management.

Denove, C. and J. D. Power IV. 2006. Satisfaction: how every great company listens to the voice of the customer. $1^{\text {st }}$ ed., Penguin Books, Ltd.

Erdem, T. and M. Keane. 1996. Decision-making under uncertainty: capturing dynamic brand choice processes in turbulent consumer markets. Marketing Science, 15(1), 1-20.

Fisher, M. L. 2004. To me it's a factory, to you it’s a store. ECR Journal, 4(2), 9-18.

Fisher M. L., C. Ittner. 1999. The impact of product variety on automobile assembly operations: empirical evidence and simulation analysis. Management Science, 45, 771-786.

Fisher, M. L. and J. Krishnan. 2005. Gotta Hava Wawa. Case study, The Wharton School, University of Pennsylvania.

Fisher, M. L., A. Raman and A. McClelland. 2000. Rocket-science retailing is almost here: are you ready? Harvard Business Review, 78(4), 115-124.

Frei, F. X. and P. T. Harker. 1999. Measuring the efficiency of service delivery processes: an application to retail banking. Journal of Service Research, 1(4), 300-312.

Frei, F. X., R. Kalakota, A. J. Leone and L. M. Marx. 1999. Process variation as determinant of bank performance: evidence from the retail banking study. Management Science, 45(9), 1210-1220.

Hise, R. T., J. P. Kelly, M. Gable and J. B. McDonald. 1983. Factors affecting the performance of individual chain store units: an empirical analysis. Journal of Retailing, 59(2), 22-39. 
Iacobucci, D., K. Grayson and A. Ostrom. 1994. The calculus of service quality and customer satisfaction: theoretical and empirical differentiation and integration, in T.A. Swartz, D.E. Bowen, and S.W. Brown, eds., Advances in Services Marketing and Management: Research and Practice, Vol. 3, Greenwich, CT: JAI Press, 1-67.

Iacobucci, D., A. Ostrom and K. Grayson. 1995. Distinguishing service quality and customer satisfaction: the voice of the consumer. Journal of Consumer Psychology, 4, 277-303.

Ittner, C. D., and D. F. Larcker. 1998. Are non-financial measures leading indicators of financial performance? An analysis of customer satisfaction. Journal of Accounting Research, 36, 1-46.

Kennedy, P. 2003. A Guide to Econometrics. $5^{\text {th }}$ ed., The MIT Press.

Lapre, M. A. and N. Tsikriktsis. 2006. Organizational learning curves for customer dissatisfaction: heterogeneity across airlines. Management Science, 52, 352-366.

MacDuffie, J. P., K. Sethuraman and M. L. Fisher. 1996. Product variety and manufacturing performance: evidence from the international automotive assembly plant study. Management Science, 42(3), 350369.

Maddala, G. S., 2001. Introduction to Econometrics. $3^{\text {rd }}$ ed., John Wiley \& Sons

Mittal, V., E. W. Anderson, A. Sayrak and P. Tadikamalla. 2005. Dual emphasis and the long-term financial impact of customer satisfaction. Marketing Science, 24(4), 544-555.

Morgan, N.A. and L.L. Rego. 2006. The value of different customer satisfaction and loyalty metrics in predicting business performance. Marketing Science, 25(5), 426-439.

Pindyck, R. S. and D. L. Rubinfeld. 1997. Econometric Models and Economic Forecasts. $4^{\text {th }}$ ed., McGraw-Hill/Irwin.

Raman, A., N. DeHoratius and Z. Ton. 2001a. The Achilles heel of supply chain management. Harvard Business Review, May, 136-152.

Raman, A., N. DeHoratius and Z. Ton. 2001b. Execution: the missing link in retail operations. California Management Review, 43(3), 136-142.

Ren, J. and X. Wang. 2006a. Process consistency and service quality in US hospitals: an empirical 
investigation. Working Paper, Boston University.

Ren, J. and X. Wang. 2006b. Volume and variability: an empirical investigation of service quality in US hospitals. Working Paper, Boston University.

Salmon, W. J. 1989. Retailing in the age of execution. Journal of Retailing, 65(3), 368-378.

Spector, R. and D. McCarthy. 1996. The Nordstrom way: the inside story of America's \#1 customer service company. Reprint ed., John Wiley \& Sons.

Sulek, J. M., M. R. Lind and A. S. Marucheck. 1995. The impact of customer service intervention and facility design on firm performance. Management Science, 41(11), 1763-1773.

Ton, Z. and R. S. Huckman. 2005. Managing the impact of employee turnover on performance: the role of process conformance. Working paper, Harvard University.

Ton, Z. and A. Raman. 2004. The effect of product variety and inventory levels on retail store operations: a longitudinal study. Working paper, Harvard University.

Tsikriktsis, N. 2006. The effect of operational performance and focus on profitability: a longitudinal study of the U.S. airline industry. Forthcoming, Manufacturing \& Service Operations Management.

Tucker, A. 2004. The impact of operational failures on hospital nurses and their patients. Journal of Operations Management, 22(2), 151-169.

Tucker, A., and A. Edmondson. 2003. Why hospitals don't learn from failures: organizational and psychological dynamics that inhibit system change. California Management Review, 45(2), 55-72.

van Donselaar, K. H., V. Gaur, T. van Woensel, R. A. C. M. Broekmeulen and J. C. Fransoo. 2006. An empirical study of ordering behavior of retail stores. Working paper, Eindhoven University of Technology.

Womack, J. P., D. T. Jones and D. Roos. 1991. The machine that changed the world: the story of lean production. Reprint ed., Harper Perennial.

Wooldridge, J. M. 2002. Econometric analysis of cross section and panel data. $1^{\text {st }}$ ed., The MIT Press. 
Table 1. Summary statistics and variable description (cross-sectional monthly averages).

\begin{tabular}{|c|c|c|c|c|c|}
\hline Variable & Min & Median & Mean & Max & Description \\
\hline \multicolumn{6}{|l|}{ Operational and financial data } \\
\hline$i$ & 1 & N/A & N/A & 437 & Store number \\
\hline$t$ & 1 & N/A & N/A & 17 & Time period (in months) \\
\hline SALES & 77,060 & 405,359 & 436,032 & $1,409,365$ & Store sales, $\$$ \\
\hline TRANSACTIONS & 1,851 & 9,330 & 10,019 & 31,016 & Number of checkout transactions \\
\hline UNITS.SOLD & 6,466 & 31,148 & 34,035 & 117,901 & Number of units of products sold \\
\hline CLEARANCE & 56 & 1,687 & 1,969 & 14,224 & Sales from products on clearance, $\$$ \\
\hline OVERRIDE & 20 & 563 & 943 & 7,949 & Sales involving managerial overrides, \$ \\
\hline RETURN & 3,628 & 66,677 & 73,027 & 232,519 & Value of product returns, $\$$ \\
\hline MOS & 580 & 7,094 & 8,117 & 36,424 & Value of products marked out of stock, \$ \\
\hline ASSOCIATE.PLAN.DOLLARS & 7,082 & 21,067 & 23,657 & 102,151 & Planned store associate payroll, \$ \\
\hline MANAGER.PLAN.DOLLARS & 6,680 & 18,568 & 20,047 & 48,896 & Planned managerial payroll, \$ \\
\hline ASSOCIATE.DOLLARS & 7,360 & 21,663 & 24,160 & 98,789 & Actual store associate payroll, $\$$ \\
\hline MANAGER.DOLLARS & 6,139 & 17,815 & 19,377 & 52,466 & Actual managerial payroll, \$ \\
\hline ASSOCIATE.TERMINATIONS & .00 & 1.45 & 1.56 & 5.78 & Number of associate terminations \\
\hline MANAGER.TERMINATIONS & .00 & .11 & .11 & 1.00 & Number of managerial terminations \\
\hline ESTIMATED.INSTOCK & .92 & .96 & .93 & .99 & Estimated in-stock product availability, \% \\
\hline \multicolumn{6}{|l|}{ Customer satisfaction survey data } \\
\hline AISLEDEBRIS & .05 & .18 & .18 & .55 & $\begin{array}{l}\text { During your visit, did anything get in your way } \\
\text { that was put or left in the aisles? }(0-1)\end{array}$ \\
\hline GREETING & .51 & .72 & .73 & .97 & $\begin{array}{l}\ldots \text { did anyone greet you and ask if they could } \\
\text { help you? }(0-1)\end{array}$ \\
\hline ASSTNEEDED & .03 & .13 & .14 & .37 & $\begin{array}{l}\ldots \text { did you need some assistance, but were } \\
\text { unable to find it? }(0-1)\end{array}$ \\
\hline CHECKOUT & .78 & .90 & .90 & .98 & ...was your checkout quick and efficient? (0-1) \\
\hline BEYONDREACH & .09 & .19 & .19 & .34 & $\begin{array}{l}\ldots \text { did you see any product in which you were } \\
\text { interested in purchasing that was too high for } \\
\text { you to reach? }(0-1)\end{array}$ \\
\hline CUSTOMER.INSTOCK & .69 & .76 & .76 & .88 & $\begin{array}{l}\text {... did you look for anything that turned out to } \\
\text { be out of stock or not carried by the store? ( } 0 \text { - } \\
\text { 1) }\end{array}$ \\
\hline FINDINGPRICE & .00 & .15 & .15 & .35 & $\begin{array}{l}\text {... did you have any difficulty finding the price } \\
\text { of an item? }(0-1)\end{array}$ \\
\hline KNOWPRODUCT & 7.63 & 8.30 & 8.30 & 9.10 & $\begin{array}{l}\text {... how knowledgeable are employees about } \\
\text { what they sell? (scale of } 1 \text { to } 10 \text { ) }\end{array}$ \\
\hline KNOWBRAND & 7.90 & 8.37 & 8.38 & 8.99 & $\begin{array}{l}\text {... how knowledgeable are employees about } \\
\text { the choice of brands? (scale of } 1 \text { to } 10 \text { ) }\end{array}$ \\
\hline KNOWPRICES & 7.03 & 7.58 & 7.58 & 8.25 & $\begin{array}{l}\text {... how knowledgeable are employees about } \\
\text { their everyday prices? (scale of } 1 \text { to } 10 \text { ) }\end{array}$ \\
\hline WILLRETURN & .95 & .99 & .99 & 1.00 & $\begin{array}{l}\text { Based on your visit to our company that day, } \\
\text { will you come back? }(0-1)\end{array}$ \\
\hline VALUE & .89 & .93 & .93 & .98 & $\begin{array}{l}\text { Do you feel that you got your money's worth } \\
\text { on this visit? }(0-1)\end{array}$ \\
\hline OVERALL.RATING & 7.90 & 8.40 & 8.40 & 9.17 & $\begin{array}{l}\text { Taking everything into account, how would } \\
\text { you rate your visit to the store that day? (scale } \\
\text { of } 1 \text { to } 10 \text { ) }\end{array}$ \\
\hline
\end{tabular}


Table 2. Correlations among independent operational and financial variables after data transformation.

\begin{tabular}{|l|r|r|r|r|r|r|r|r|}
\hline Variable name & 1 & 2 & 3 & 4 & 5 & 6 & 7 & 8 \\
\hline 1. CLEARANCE & 1.00 & & & & & & & \\
\hline 2. OVERRIDE & .15 & 1.00 & & & & & & \\
\hline 3. MOS & .19 & .18 & 1.00 & & & & & \\
\hline 4. ASSOCIATE.DOLLARS & .16 & .12 & .40 & 1.00 & & & & \\
\hline 5. MANAGER.DOLLARS & .21 & .19 & .44 & .64 & 1.00 & & & \\
\hline 6. ASSOCIATE.TERMINATIONS & .10 & .08 & .17 & .09 & .16 & 1.00 & & \\
\hline 7. MANAGER.TERMINATIONS & .02 & .02 & .03 & .03 & -.04 & .06 & 1.00 & \\
\hline 8. ESTIMATED.INSTOCK & .22 & .20 & .50 & .84 & .79 & .17 & .04 & 1.00 \\
\hline
\end{tabular}

Table 3. Correlations among independent variables in the satisfaction survey after data transformation.

\begin{tabular}{|c|c|c|c|c|c|c|c|}
\hline Variable name & 1 & 2 & 3 & 4 & 5 & 6 & 7 \\
\hline 1. TOTKNOWLEDGE & 1.00 & & & & & & \\
\hline 2. AISLEDEBRIS & .23 & 1.00 & & & & & \\
\hline 3. GREETING & .81 & .19 & 1.00 & & & & \\
\hline 4. ASSTNEEDED & .23 & .25 & .16 & 1.00 & & & \\
\hline 5. CHECKOUT & .92 & .22 & .78 & .21 & 1.00 & & \\
\hline 6. BEYONDREACH & .37 & .29 & .31 & .30 & .36 & 1.00 & \\
\hline 7. FINDINGPRICE & .23 & .26 & .17 & .25 & .22 & .28 & 1.00 \\
\hline
\end{tabular}

Table 4a. Estimation results for SALES.

\begin{tabular}{|l|l|l|l|l|}
\hline \multirow{2}{*}{ Independent Variables } & \multicolumn{2}{c|}{$\begin{array}{c}\text { SUR } \\
\text { (POLS estimator) }\end{array}$} & \multicolumn{2}{c|}{$\begin{array}{c}\text { 2SLS } \\
\text { (IV estimator) }\end{array}$} \\
\cline { 2 - 5 } & Estimate & t value & Estimate & t value \\
\hline ASSOCIATE.DOLLARS & $.493^{* * *}$ & 40.31 & $.483^{* * *}$ & 38.99 \\
\hline OVERALL.RATING & $.138^{* * *}$ & 6.67 & $.202^{* * *}$ & 8.17 \\
\hline ESTIMATED.INSTOCK & $.223^{* * *}$ & 10.38 & $.176^{* * *}$ & 7.39 \\
\hline CLEARANCE & $.044^{* * *}$ & 6.66 & $.043^{* * *}$ & 6.56 \\
\hline MANAGERS.DOLLARS & $.045^{* * *}$ & 4.31 & $.040^{* * *}$ & 3.82 \\
\hline MANAGERS.TERMINATIONS & $-.013^{*}$ & -1.74 & -.013 & -1.77 \\
\hline ASSOCIATE.TERMINATIONS & .007 & 1.06 & .006 & .89 \\
\hline OVERRIDE & .002 & .25 & .001 & .10 \\
\hline MOS & .004 & .58 & .003 & .34 \\
\hline $\mathrm{R}^{2}(\%)$ & $74.6 \%$ & NA & NA & NA \\
\hline $\mathrm{p}$-value of regression & 0 & NA & NA & NA \\
\hline
\end{tabular}

$* * *$ Statistically significant at $\mathrm{p}<0.01, * *$ Statistically significant at $\mathrm{p}<0.05, *$ Statistically significant at $\mathrm{p}<0.10$. 
Table 4b. Estimation results for OVERALL.RATING.

\begin{tabular}{|l|l|l|l|l|}
\hline \multirow{2}{*}{ Independent Variables } & \multicolumn{2}{c|}{$\begin{array}{c}\text { SUR } \\
\text { (POLS estimator) }\end{array}$} & \multicolumn{2}{c|}{$\begin{array}{c}\text { 2SLS } \\
\text { (IV estimator) }\end{array}$} \\
\cline { 2 - 5 } & Estimate & t value & Estimate & t value \\
\hline TOTKNOWLEDGE & $.792^{* * *}$ & 105.16 & $.571^{* * *}$ & 14.84 \\
\hline CUSTOMER.INSTOCK & $.046^{* * *}$ & 11.45 & $.399^{* * *}$ & 6.75 \\
\hline CHECKOUT & $.105^{* * *}$ & 18.50 & $.064^{* * *}$ & 5.85 \\
\hline GREETING & $.046^{* * *}$ & 12.50 & $.032^{* * *}$ & 5.32 \\
\hline ASSOCIATE.DOLLARS & $.017^{* * *}$ & 4.35 & $.018^{* * *}$ & 2.99 \\
\hline FINDINGPRICE & $-.005^{* *}$ & -2.22 & $-.018^{* * *}$ & -4.40 \\
\hline MOS & .003 & 1.16 & $-.015^{* * *}$ & -3.07 \\
\hline MANAGERS.DOLLARS & $.010^{* * *}$ & 2.87 & -.008 & -1.36 \\
\hline ASSTNEEDED & $-.011^{* * *}$ & -4.60 & -.005 & -1.49 \\
\hline ASSOCIATE.TERMINATIONS & .002 & .89 & -.005 & -1.42 \\
\hline MANAGERS.TERMINATIONS & .002 & .86 & .002 & .41 \\
\hline BEYONDREACH & -.002 & -.70 & -.002 & -.52 \\
\hline AISLEDEBRIS & -.004 & -1.83 &.- .003 & -.92 \\
\hline $\mathrm{R}^{2}$ & $97.1 \%$ & $\mathrm{NA}$ & $\mathrm{NA}$ & $\mathrm{NA}$ \\
\hline p-value & 0 & $\mathrm{NA}$ & $\mathrm{NA}$ & $\mathrm{NA}$ \\
\hline
\end{tabular}

$* * *$ Statistically significant at $\mathrm{p}<0.01, * *$ Statistically significant at $\mathrm{p}<0.05,{ }^{*}$ Statistically significant at $\mathrm{p}<0.10$.

Table 4c. Estimation results for CUSTOMER.INSTOCK.

\begin{tabular}{|l|l|l|l|l|}
\hline \multirow{2}{*}{ Independent Variables } & \multicolumn{2}{c|}{$\begin{array}{c}\text { SUR } \\
\text { (POLS estimator) }\end{array}$} & \multicolumn{2}{c|}{$\begin{array}{c}\text { 2SLS } \\
\text { (IVstimator) }\end{array}$} \\
\cline { 2 - 5 } & Estimate & t value & Estimate & t value \\
\hline TOTKNOWLEDGE & $.597^{* * *}$ & 24.89 & $.597^{* * *}$ & 24.89 \\
\hline ESTIMATED.INSTOCK & $.218^{* * *}$ & 11.05 & $.218^{* * *}$ & 11.05 \\
\hline MOS & $.049^{* * *}$ & 6.21 & $.049^{* * *}$ & 6.21 \\
\hline MANAGERS.DOLLARS & $.032^{* * *}$ & 4.67 & $.032^{* * *}$ & 4.67 \\
\hline FINDINGPRICE & $.031^{* * *}$ & 4.57 & $.031^{* * *}$ & 4.57 \\
\hline ASSTNEEDED & $-.021^{* * *}$ & -2.44 & $-.021^{* * *}$ & -2.44 \\
\hline ESTIMATED.INSTOCK:ASSOCIATE.DOLLARS & $-.056^{* * *}$ & -5.03 & $-.056^{* * *}$ & -5.03 \\
\hline ASSOCIATE.DOLLARS:TOTKNOWLEDGE & $.041^{* * *}$ & 3.59 & $.041^{* * *}$ & 3.59 \\
\hline ASSOCIATE.DOLLARS & -.021 & -1.46 & -.021 & -1.46 \\
\hline AISLEDEBRIS & -.005 & -.40 & -.005 & -.40 \\
\hline BEYONDREACH & -.003 & .35 & -.003 & .35 \\
\hline $\mathrm{R}^{2}$ & $71.34 \%$ & $\mathrm{NA}$ & $\mathrm{NA}$ & $\mathrm{NA}$ \\
\hline p-value & 0 & $\mathrm{NA}$ & $\mathrm{NA}$ & $\mathrm{NA}$ \\
\hline
\end{tabular}

$* * *$ Statistically significant at $\mathrm{p}<0.01, * *$ Statistically significant at $\mathrm{p}<0.05, *$ Statistically significant at $\mathrm{p}<0.10$. 
Figure 1. Sales influence diagram based on 2-stage least squares estimation.

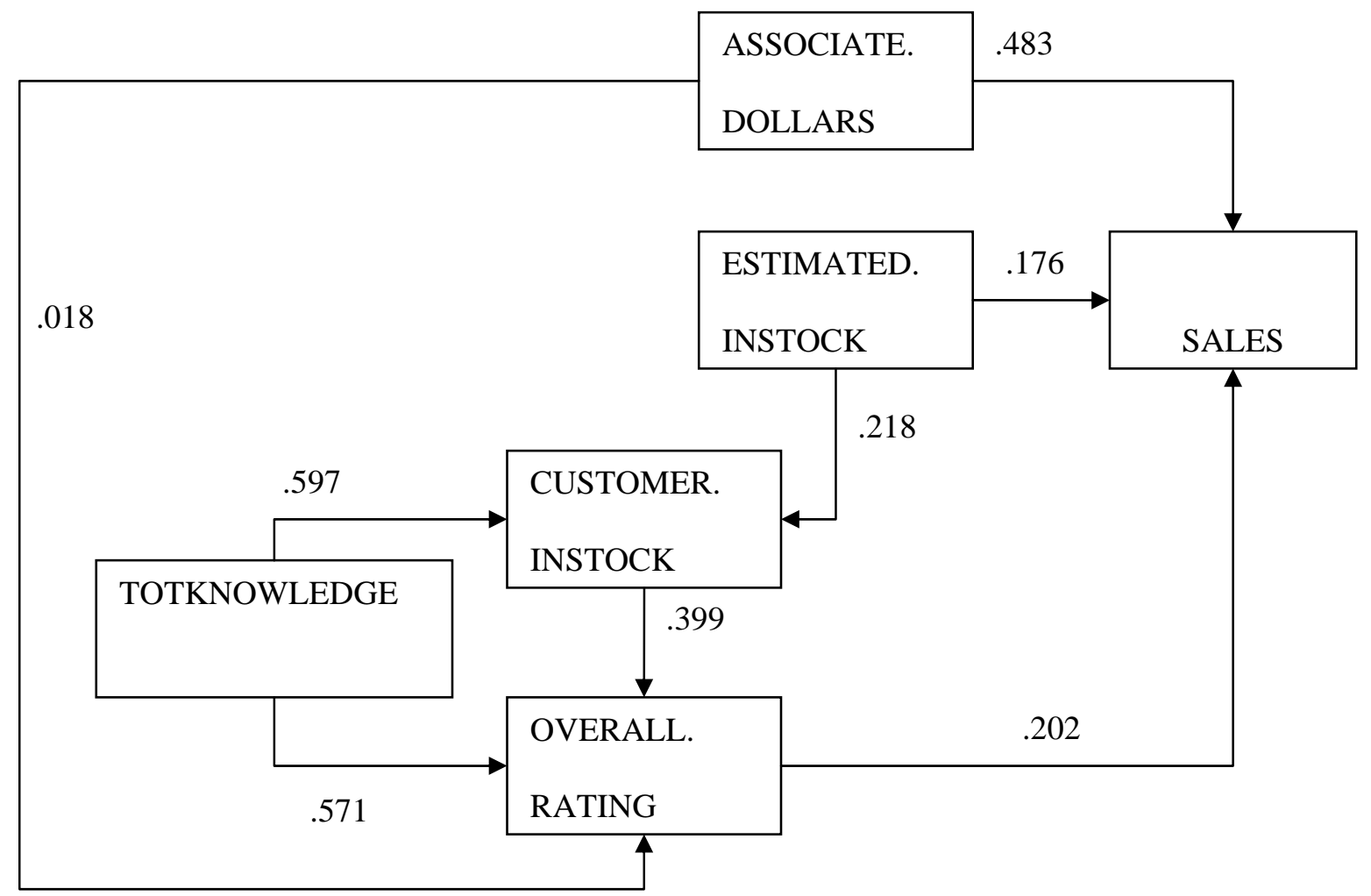

Figure 2. Conceptual model of store operations.

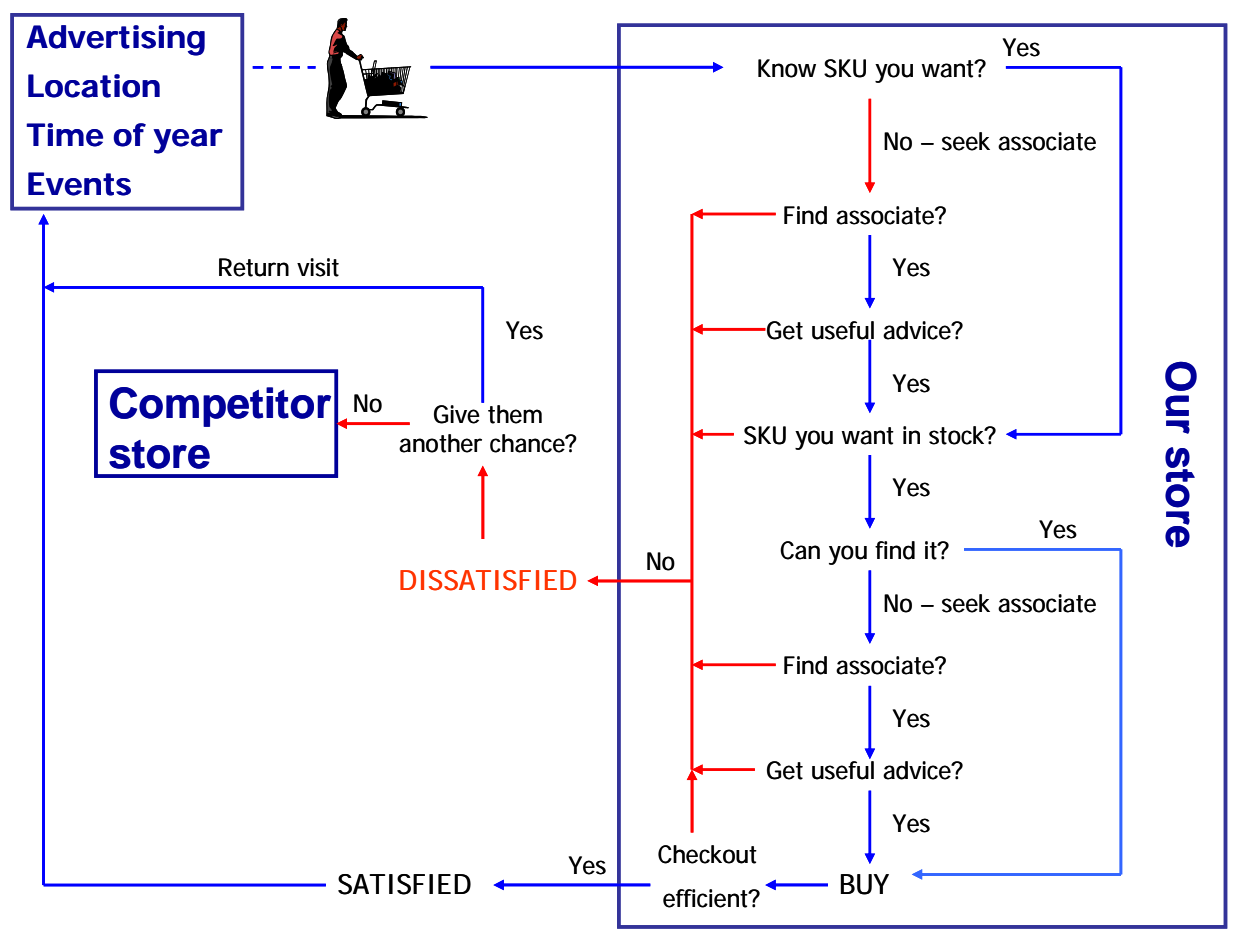


Figure 3. Sales vs. associate payroll for a particular store.

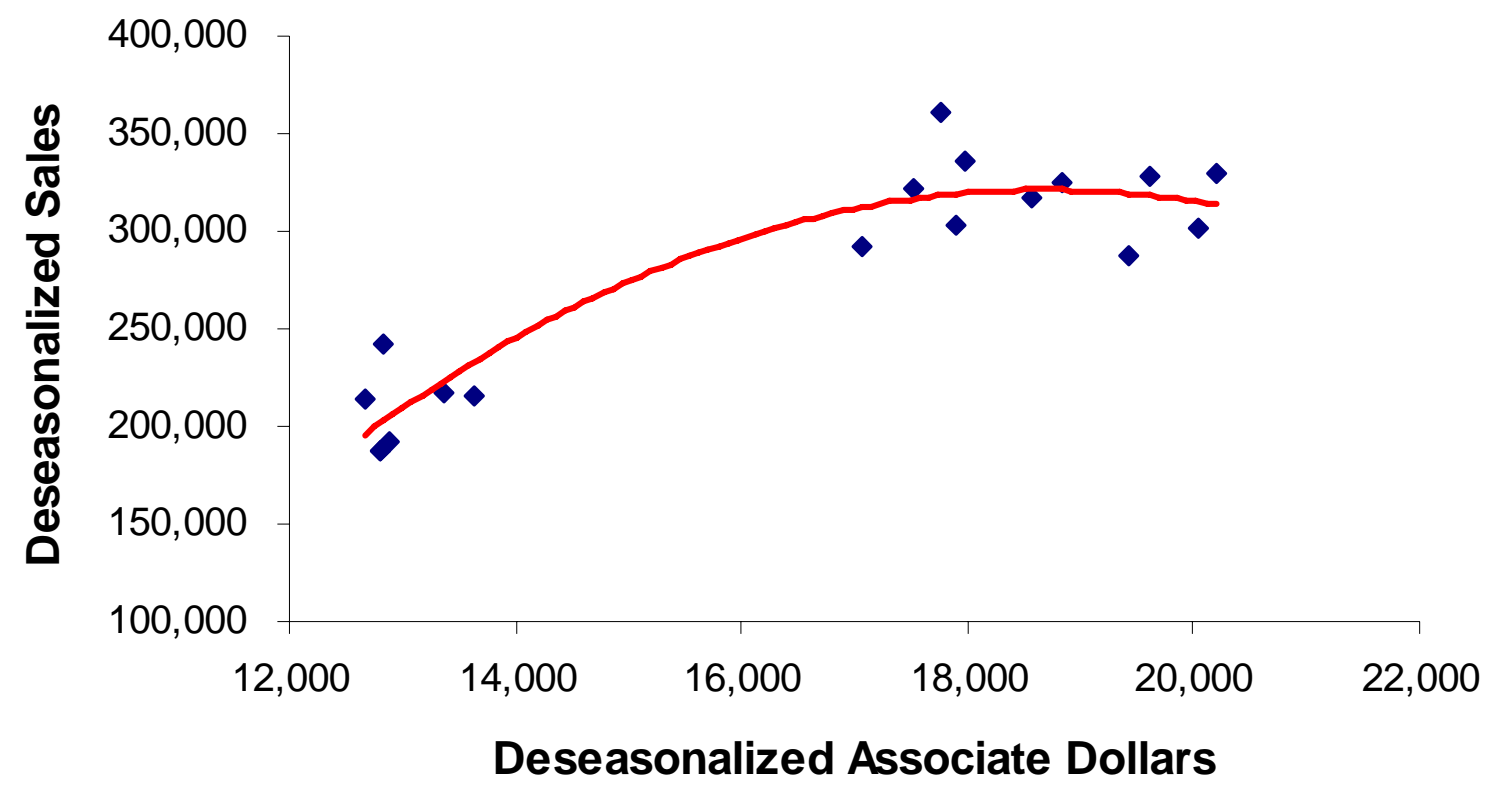

